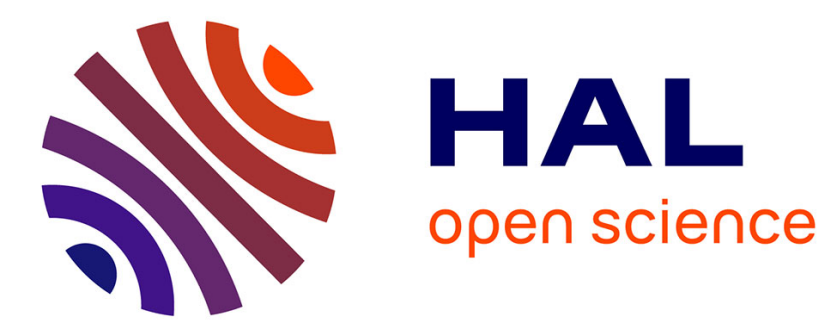

\title{
Large complexes: Cloning strategy, production and purification
}

\author{
Eric Durand, Roland Lloubès
}

\section{To cite this version:}

Eric Durand, Roland Lloubès. Large complexes: Cloning strategy, production and purification. Methods in Molecular Biology: Bacterial protein secretion systems, 2017, 10.1007/978-1-4939-7033-9_24 . hal-01788569

\section{HAL Id: hal-01788569 \\ https://hal-amu.archives-ouvertes.fr/hal-01788569}

Submitted on 9 May 2018

HAL is a multi-disciplinary open access archive for the deposit and dissemination of scientific research documents, whether they are published or not. The documents may come from teaching and research institutions in France or abroad, or from public or private research centers.
L'archive ouverte pluridisciplinaire HAL, est destinée au dépôt et à la diffusion de documents scientifiques de niveau recherche, publiés ou non, émanant des établissements d'enseignement et de recherche français ou étrangers, des laboratoires publics ou privés. 


\section{Chapter 24. Large complexes: Cloning strategy, production and purification}

2Running Head: Membrane protein complex purification

3Eric Durand and Roland Lloubes

4attention abbreviations

5Laboratoire d'Ingénierie des Systèmes Macromoléculaires UMR7255, Institut de Microbiologie 6de la Méditerranée, CNRS/Aix-Marseille Université, 31 chemin Joseph Aiguier, 13402 Marseille 7 cedex 20, France

8

9E-mail: roland.1loubes@imm.cnrs.fr

10

\section{1i. Summary}

12Membrane proteins can assemble and form complexes in the cell envelope. In Gram-negative 13bacteria, a number of multiprotein complexes including secretion systems, efflux pumps, 14molecular motors or pilus assembly machines comprise proteins from the inner and the outer 15 membrane. Beside the structures of isolated soluble domains, only few atomic structures of these 16assembled molecular machines have been elucidated. To better understand the function and to 17solve the structure of protein complexes, it is thus necessary to design dedicated production and 18purification processes. Here, we present cloning procedures to overproduce membrane proteins 19into E. coli cells and describe the cloning and purification strategy for the Type VI secretion 20TssJLM membrane complex.

21

22ii. Key words: membrane protein complexes, E. coli, T7 overexpression, protein purification. 23

\section{Introduction}

25Protein overproduction results from cloning a gene of interest into a plasmid vector, downstream 26of a tightly regulated promoter, and from inducing its expression after plasmid transformation 
27into a bacterial strain. For large protein complexes containing multiple subunits, the genes 28encoding the different subunits can be expressed under the control of an inducible promoter 29either from single plasmid containing a cluster of genes or from different compatible plasmids 30harboring single or multiple genes.

\subsection{Cloning vectors}

32Several inducible promoters have been described and are available to overexpress a gene of 33interest. These promoters are usually cloned into vectors that also contain the gene encoding the 34cognate regulatory protein and a transcriptional terminator to prevent non-productive 35 transcription from downstream gene (1-7). The tac and trc promoters that contain the -35 and -10 36sequences from the trp and lacUV5 promoters, respectively, have been optimized for high 37expression level (1). Other E. coli tightly regulated promoters such as the tetA promoter and its 38repressor TetR, the araBAD promoter and its cognate activator AraC (3-6). In addition, 39heterologous combinations of promoter/regulator binding sequences can be used (2). The last 40family of inducible promoters gathers sequences that are not recognized by the E. coli RNA 41polymerase but rather recognized by phage RNA polymerases such as the SP6, T3 and T7 42promoters. Vectors and strains that express the T7 RNA polymerase (T7RNAp) have been 43extensively developed. Three independent methods are used to regulate the $\mathrm{T} 7$ expression 44systems. First, the expression of the chromosomally- or plasmid-encoded T7 RNAp gene can be 45itself under the control of an inducible promoter (see Note 1). Second, the inhibition of the T7 46RNAp basal activity can be controlled by producing the T7 lysozyme under constitutive or 47regulated conditions $(\mathbf{8}, \mathbf{9})$. Last, the transcription by the T7 RNAp can be repressed by the Lac 48repressor, adding the lac operator sequence (10), the lacI gene being cloned on the expression 49vector. 
51A large choice of cloning vectors with different characteristics is now available and can be 52selected based on the toxicity, stability and folding rate of the protein or protein complex to 53overproduce:

54- production of proteins in the cytoplasm, the periplasm or the membrane of E. coli (using the 55addition of synthetic N-terminal signal-sequences such as that of the OmpA and PelB proteins). 56- compatible $\mathrm{T} 7$ expression vectors containing one or two $\mathrm{T} 7$ promoters to overproduce protein 57complexes with up to eight subunits (see Duet Vectors from Novagen).

58- Protein tagging sequence (6 to $10 \times$ His, Strep-Tag II...) or fusion partner (protein G, 59glutathione-S-transferase: GST, calmodulin-binding peptide: CBP, Maltose binding protein: $60 \mathrm{MBP})$ to increase protein solubility or to simplify the purification using affinity chromatography 61techniques. In addition, these tag affinity sequences can be removed using specific protease 62(most used proteases: Tobacco Etch Virus Protease: TEV, enterokinase, Thrombin, Xa Factor, 63PreScission..). For this purpose, the corresponding protease recognition sequence is inserted 64either downstream (for N-terminal tagging) or upstream (for C-terminal tagging) of the tag 65sequence. After protease digestion, purified protein complex is submitted to a new purification 66step to remove the protease, the uncleaved protein and the tag peptide (for example affinity 67chromatography to remove the His-tag peptide and the His-tagged TEV).

68 Currently, cloning into these vectors is facilitated by PCR techniques based on gene and 69plasmid amplifications, leading to restriction site/ligation free cloning methods. These techniques 70have proven to be efficient to perform gene expression strategies in short delay (see section 3.1 71and Note 2).

72 If none of the overproduction strategies are sufficient to produce and purify protein 73complexes, in vitro alternatives such as cell-free transcription-translation systems, based on 
74T7RNAp and E. coli cell extracts, have been found efficient to produce milligram amounts of 75some membrane proteins (11).

76

\subsection{Membrane protein complex overproduction and purification}

$78 \mathrm{Membrane}$ protein complexes have been successfully overproduced and purified based on $\mathrm{pBAD}$ 79or T7 vectors. For example, the Tol proteins from the Tol cell envelope molecular motor were 80overproduced and specifically radiolabeled with ${ }^{35}$ S-Methionine after cloning into a pT7-driven 81vector using restriction sites (RS) and ligation techniques $(\mathrm{RSl})(\mathbf{1 2}, \mathbf{1 3}$, see Note 3 and Note 4). 82Sub-complexes from the Ton system (14-17), the PomA-PomB flagellar rotor (18), the AcrAB83TolC efflux pump (19), the Type IV and Type VI secretion systems (T4SS and T6SS, 84respectively; 20, 21) and the $\beta$-barrel assembly machinery (22) have been also successfully 85purified using similar approaches.

86 In addition to the cloning strategy and the production to levels compatible with 87purification, studying these multiprotein machines also requires to extract and solubilize the 88protein complex without disrupting the contacts between the subunits. Finally, since the 89overproduction condition may induce stoichiometry artifacts, the tagging of the minor subunit or 90the specific tagging of different subunits should be performed to purify homogenous protein 91complexes (see below and section 3.2).

92 Here we describe the cloning strategy as well as the production, extraction, and 93purification of the T6SS TssJLM membrane complex (21).

94

\section{Materials}

962.1 Cloning of the TssJLM complex 
971. Desalted oligonucleotides of up to 35 bases, 5' ends unphosphorylated

982. Restriction enzymes (NdeI, XhoI, DpnI)

993. T4 DNA ligase

1004. Thermoblock $\left(16^{\circ} \mathrm{C}-42^{\circ} \mathrm{C}\right)$

1015. E. coli $\mathrm{DH} 5 \alpha$ competent cells

1026. PCR thermocycler

1037. HPLC purified Mega-primer pairs ( $\geq 50$ bases), 5' ends unphosphorylated

1048. vector: pRSF-Duet1

1059. High fidelity Taq DNA polymerase (Pfu turbo, Agilent)

10610. dNTPs, $10 \mathrm{mM}$ stock solution in water

10711. Agarose gel electrophoresis system

1082.2 Production and purification of the TsSJLM complex

1091. IPTG stock solution: $0.1 \mathrm{M}$ in water

1102. BL21(DE3): E. coli strain B $\mathrm{F}^{-}$ompT gal dcm lon $h s d S_{B}\left(r_{B}{ }^{-} m_{B}{ }^{-}\right) \lambda(\mathrm{DE} 3$ [lacI lacUV5-T7 gene

1111 ind1 $\operatorname{sam} 7$ nin5]) $\left[\mathrm{malB}^{+}\right]\left(\lambda^{\mathrm{S}}\right)$

1123. Lysozyme stock solution: $10 \mathrm{mg} / \mathrm{mL}$ in water

1134. DNase stock solution: $10 \mathrm{mg} / \mathrm{mL}$ in water

1145. TCEP (Tris(2-carboxyethyl)phosphine hydrochloride) extemporaneously added

1156. EDTA stock solution: $0.5 \mathrm{M}$ in water

1167. $\mathrm{MgCl}_{2}$ stock solution: $1 \mathrm{M}$ in water

1178. Lysis buffer: 50 mM Tris-HCl, pH 8.0, 50 mM NaCl, 1 mM EDTA 
1189. Solubilization buffer: $50 \mathrm{mM}$ Tris- $\mathrm{HCl}, \mathrm{pH} 8.0,50 \mathrm{mM} \mathrm{NaCl}, 1 \mathrm{mM}$ EDTA, $0.5 \%$ (w/v) n119dodecyl- $\beta$-D-maltopyranoside (DDM), 0.75\% (w/v) decyl maltose neopentyl glycol (DM-NPG), $1200.5 \%(\mathrm{w} / \mathrm{v})$ digitonin (Sigma-Aldrich)

12110. EDTA-free protease inhibitor tablets

122110. Affinity buffer: $50 \mathrm{mM}$ Tris-HCl, $\mathrm{pH} 8.0,50 \mathrm{mM} \mathrm{NaCl}, 0.05 \%$ (w/v) DM-NPG

12312. Imidazole-HCl, $\mathrm{pH} 8.0$ : stock solution $4 \mathrm{M}$

12413. Incubation Shakers $\left(16^{\circ}-37^{\circ} \mathrm{C}\right)$

12514. Centrifugation (from 5,000 to $100,000 \times \mathrm{g}$ )

12615. Glass potter

12716. Emulsiflex-C5 (Avestin)

12817. 5-mL StrepTrap HP and 5-ml HisTrap HP columns (GE Healthcare)

12918. Desthiobiotin

130

1313. Methods

1323.1: Cloning the TssJLM membrane complex

133To overproduce the T6SS TssJLM membrane complex, the tssJ, tssL and tss $M$ genes have been 134assembled in an artificial operon with individual optimized ribosome-binding sites (see Figure 1351). In addition, based on previous data regarding permissive positions, each subunit has been 136tagged with a specific tag.

137 The pRSF-Tss J ${ }^{\text {Strep-TssL }}{ }^{\text {FLAG_His6 }}$ TssM plasmid was constructed by both RSl (see Note 1384) and RS1-free (see Note 2, (23)) cloning methods (Figure 1).

1391. PCR amplify the $t s s J$ gene (encoding the TssJ lipoprotein) using High fidelity Taq DNA 140polymerase and primers containing the NdeI (5' primer) and the XhoI RS (3' primer) extensions. 
141The Strep-Tag II DNA sequence followed by a stop codon was introduced in the 3' primer (Note 1425). Check the correct amplification by agarose gel electrophoresis (AGE).

1432. Digest the PCR product and the pRSF-Duet vector with NdeI and XhoI restriction enzymes 144(sites present into the pRSF-Duet MCS2).3. Mix the digested PCR amplified fragment with 145about $50 \mathrm{ng}$ of the digested pRSF-Duet vector, both digested with NdeI and XhoI, with a molar 146excess ratio of insert/vector of (2/1 to 5/1, inversely proportional to the DNA length of the 147insert).

1484. Add $1 \mathrm{U}$ of T4 DNA ligase to the DNA mixture plus its specific buffer in a total volume of 15 $149 \mu \mathrm{l}$ and incubate at $16-20^{\circ} \mathrm{C}$ for at least 2 hours.

1505. Transform E. coli DH5 $\alpha$ competent cells with about $30 \%$ of the ligation mix, plate on LB agar 151 containing the appropriate antibiotic (in case of pRSF-Duet, use kanamycin $50 \mu \mathrm{g} / \mathrm{mL}$ ) and 152incubate overnight at $37^{\circ} \mathrm{C}$.

1536. Select positive clones containing the $\mathrm{pRSF}-\mathrm{Tss}^{\mathrm{Strep}}$ plasmid by colony PCR screening using 154the same primers. Extract the plasmid DNA and check the accuracy of the cloned sequence by 155DNA sequencing.

1567. PCR amplify the $t s s L$ gene using (i) a 5 ' primer containing a 5 ' extension (22bp) corresponding 157to the Strep-TagII and the stop codon followed by the RBS sequence (see Note 6) and the 5'158FLAG-tssL extension (63bp), and (ii) a 3' primer containing the 3 '-tssL gene extension (35bp) 159including the stop codon followed by RBS, the ATG and the 5'-His6-tssM extension (14bp). 160Check correct amplification by AGE. 1618. PCR amplify the $t s s M$ gene using (i) the 5 ' primer complementary to the 3 ' end of $t s s L$ gene, 162RBS, His tag and 5' sequence of $t s s M$ gene (20bp) and (ii) the 3 ' primer containing the $3^{\prime}-t s s M$ 
163gene extension (35bp) including the stop codon followed by the pRSF-Duet sequence extension 164(35bp). Check correct amplification by AGE.

1659. Mix the flag-tssL, his-tssM PCR products and the pRSF-TssJ ${ }^{\text {Strep }}$ plasmid and PCR amplify 166with High fidelity DNA polymerase in a single reaction as described for the RSl-free technique 167(see Note 2).

16810. Digest the mixture with DpnI. Transform into E. coli DH5 $\alpha$ competent cells and plate on LB 169agar containing the appropriate antibiotic and incubate overnight at $37^{\circ} \mathrm{C}$.

17011. Select positive clones containing the pRSF-Tss J ${ }^{\text {Strep_FLAG }}{ }^{2}$ ssL-6His $T s s M$ plasmid by colony 171PCR screening using the same primers. Extract the plasmid DNA and check the accuracy of the 172cloned sequence by DNA sequencing.

173

1743.2: TssJLM membrane complex, extraction and purification

1751. Transform the expression vector (pRSF-Tss J ${ }^{\text {Strep_FLAGTssL_6His }}{ }^{6}$ TsM) into the E. coli 176BL21(DE3) expression strain.

1772. Grow cells at $37^{\circ} \mathrm{C}$ in $8 \mathrm{~L}$ of lysogeny broth (LB) to an optical density at $600 \mathrm{~nm}\left(A_{600}\right) \sim 0.7$. 178Induce the expression of the $t s S L M$ genes with $1.0 \mathrm{mM} \mathrm{IPTG}$ for $16 \mathrm{~h}$ at $16^{\circ} \mathrm{C}$ (see Note 7). 1793. Pellet cells by centrifugation at 7,000 $\times \mathrm{g}$ for $20 \mathrm{~min}$. Resuspend cell pellets in $300 \mathrm{~mL}$ of ice180cold Lysis buffer supplemented with $1 \mathrm{mM}$ TCEP, $100 \mu \mathrm{g} / \mathrm{mL}$ of DNase I, $100 \mu \mathrm{g} / \mathrm{mL}$ of 181lysozyme and with one tablet of EDTA-free protease inhibitor. Add $\mathrm{MgCl}_{2}$ to the final 182concentration of $10 \mathrm{mM}$.

1834. Break the cell suspension with an Emulsiflex-C5 by 4 passages at 15,000 psi (100 MPa). 184Pellet unbroken cells by centrifugation at 7,000 $\times \mathrm{g}($ see Note 8).

1855. Pellet membranes by ultracentrifugation at $98,000 \times \mathrm{g}$ for $45 \mathrm{~min}$. 
1866. Resuspend membranes in $120 \mathrm{~mL}$ of Solubilization buffer supplemented with $1 \mathrm{mM}$ TCEP at $18722^{\circ} \mathrm{C}$ and homogenize membranes mechanically with a potter (duration about $45 \mathrm{~min}$ ) (see Note 1889).

1897. Clarify the membrane suspension by centrifugation at $98,000 \times \mathrm{g}$ for $20 \mathrm{~min}$.

1908. Load the supernatant onto a 5-mL StrepTrap HP column and then wash with Affinity buffer at $1914^{\circ} \mathrm{C}$.

1929. Elute the TssJLM core complex in Affinity buffer supplemented with $2.5 \mathrm{mM}$ desthiobiotin 193into a 5-mL HisTrap HP column.

19410. Wash the HisTrap HP column in Affinity buffer supplemented with $20 \mathrm{mM}$ imidazole and 195proceed to the elution of the TssJLM core complex in the same buffer supplemented with 500 196mM imidazole.

19711. Pool the peak fractions and load onto a Superose $610 / 300$ column equilibrated in $50 \mathrm{mM}$ 198Tris-HCl, $\mathrm{pH}$ 8.0, $50 \mathrm{mM} \mathrm{NaCl}, 0.025 \%$ (w/v) DM-NPG (see Note 10). The TssJLM complex 199elute as a single monodisperse peak close to the void volume of the column.

200

2014. Notes

2021. E. coli T7RNAp expression systems result from (i) plasmid (pGP1-2) expression, the 203T7RNAp under the control of the Lambda $P_{L}$ promoter is regulated by the plasmid encoded 204temperature-sensitive C1-857 repressor (24); (ii) chromosomal expression: the T7RNAp gene is 205under the control of the lacUV5 (25) or the ara promoter (26); (iii) besides tight control of the 206chromosomal T7RNAp expression upon AraC control (26), infection by phages (M13 mGP1-2 207or Lambda CE6) encoding the T7RNAp $(27,28)$ has proven to be efficient for the expression of 208toxic gene products. 
2092. The-RSl-free cloning strategy allows the insertion of a gene at a precise position on a target 210plasmid but does not require the presence of RS. The restriction free cloning method consists in 211 two sequential PCR amplifications using only two primers. These primers (with $\geq 25 \mathrm{bp}$ 212homology extension) are designed to hybridize on the $5^{\prime}$ and $3^{\prime}$ ends of the gene of interest and 213contain additional extension to hybridize on the expression vector at a selected position 214downstream of the regulate promoter sequence. First, the gene of interest is amplified by PCR, 215then the amplified mega-primer pairs containing the gene are annealed to the vector of interest. A 216new amplification with High fidelity polymerase produce a linear gene-vector amplification (29). 217The gene is thus plasmid included into a nicked and circular DNA molecule. The PCR reaction is 218treated by DpnI RE to digest the unwanted Dam methylated plasmids templates. Competent 219E.coli cells are further transformed with the annealed DNA complex directly. An alternative220method has been developed (30). It uses PCR amplified gene containing at least 15 bp extensions 221 that are homolog to each end of the linearized vector (PCR amplified or RS digested). PCR DNA 222and vector treated with $\mathrm{T} 4$ polymerase, to create 5 ' overhangs, are annealed to form a 223recombinant plasmid.

2243. Addition of a T7 promoter by a RS-dependent cloning strategy. RS present in the upstream 225sequence of the gene of interest can be used to insert a synthetic T7 promoter DNA fragment 226which is formed by two overlapping oligonucleotides containing the $\mathrm{T} 7$ consensus promoter 227 sequence of 23 bases corresponding to: 5'-taatacgactcactatagggaga-3'. The T7 promoter sequence 228is inserted upstream of the Ribosome Binding Site (RBS) of the gene of interest (it is also 229possible to insert the T7 promoter upstream of the natural promoter sequence). For this purpose, 230the synthetic DNA fragment contains additional 5' and 3' end extensions that are complementary 231 of the sticky ends of the RS present in the plasmid (blunt ended RS are also possible to use but 
232with lower ligation efficiency and random insertion). Two complementary desalted 233oligonucleotides $(\mathrm{ON})$ of about 35 bases, $5^{\prime}$ end unphosphorylated are hybridized following heat 234denaturation in ultrapure water and further cooling at room temperature. The annealed DNA 235fragment is further ligated into RS digested plasmid. It is possible to favor the selection of 236positive clones using Synthetic DNA that do not recreate the initial RS. Then, heat inactivated 237ligation mix is digested with the RE corresponding to the RS that has been destroyed upon DNA 238fragment ligation (Example: DNA fragment insertion into the EcoRI RS: after EcoRI digestion, 239the overhang EcoRI: 5'-AATTC... should be filled with the synthetic sequence: 5'-AATTX...., 240where the $\mathrm{X}$ nucleotide does not correspond to C nucleotide). It is noticeable that this fast 241technique does not require plasmid sequencing. It should be used for plasmids harboring 242resistance and regulatory genes in the opposite orientation from that of the $\mathrm{T} 7$ regulated gene(s) 243(31).

2444. The general RSl-dependent strategy is often used for cloning genes of interest into the MCS of 245expression vectors. The genes can be either purified from RS digestion (32) or obtained from 246PCR amplification using primers that contain additional RS extensions. Then, the PCR amplified 247DNA is RE digested and inserted into the cognate RS of the MCS present in the vector (16). 2485. Since lipoproteins undergo a post-translational modification at their N-termini (33), the Strep249Tag II affinity tag sequence was introduced at the C-terminal of TssJ. It is important to note that 250the positions of affinity tags (Strep, FLAG and His Tags) have been rationally chosen to 251maintain functional proteins.

2526. To optimize the production of the TssL and TssM protein, the endogenous RBS-ATG 5' 253sequence in front of the genes were replaced (in the 5' primer sequence) by the consensual 
254sequence “AAGGAGATATACATATG” (34) (RBS and start codon are presented, bold and 255italic letters respectively).

2567 . Growth and induction at $37^{\circ} \mathrm{C}$ for 3 hours led to very low biomass and protein yield. The 257culture was conducted at $37^{\circ} \mathrm{C}$ until $A_{600} \sim 0.7-0.9$ before shifting the incubator at $16^{\circ} \mathrm{C}$ prior to 258induction by IPTG. The final OD after the $16 \mathrm{H}$ induction was around 1.4-1.6. It is important not 259to induce around 0.4 OD since the cell would stop growing shortly after.

2608. It is important to note that whereas many cell disrupting protocol have been tried, only lysis 261with Emulsiflex produced a stable and homogenous sample of the TssJLM membrane core 262 complex.

2639. This specific combination of detergents (same recipe than that used for the purification of the 264T4SS (20)) gave the higher extraction yield of the TssJLM membrane complex. Other isolated

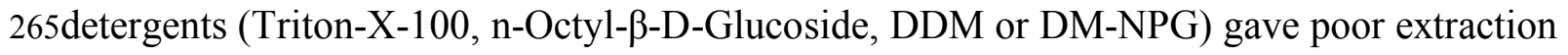
266yields. All detergent buffers were prepared extemporally the day of the purification. Digitonin 267tends to precipitate in high salt buffers and without other detergents. Adding DDM and DM268NPG prevent digitonin precipitation.

26910. DM-NPG was chosen because the solulilized TssJLM complex is stable and since this 270detergent is successful for high-resolution structural biology studies giving very clear and 271reproducible EM background after negative staining. Using low salt concentration (50 mM 272maximum) was key to prevent aggregation of the TssJLM complex. The affinity purification 273steps were of paramount importance to isolate a stoichiometric complex. Indeed, a far excess of 274the TssJ lipoprotein was eliminated during the second His column.

275

2765. References 
2771. Amann E, Brosius J, Ptashne M. (1983) Vectors bearing a hybrid trp-lac promoter useful for 278regulated expression of cloned genes in Escherichia coli. Gene 25, 167-178.

2792. Lutz R, Bujard H. (1997) Independent and tight regulation of transcriptional units in 280Escherichia coli via the LacR/O, the TetR/O and AraC/I1-I2 regulatory elements. Nucleic Acids $281 \operatorname{Res} 25,1203-1210$.

2823. Cagnon C, Valverde V, Masson JM. (1991) A new family of sugar-inducible expression 283vectors for Escherichia coli. Protein Eng 4, 843-847.

2844. Skerra A. (1994) Use of the tetracycline promoter for the tightly regulated production of a 285murine antibody fragment in Escherichia coli. Gene 151,131-135.

2865. Guzman LM, Belin D, Carson MJ, Beckwith J. (1995) Tight regulation, modulation, and high287level expression by vectors containing the arabinose PBAD promoter. J Bacteriol 177, 41212884130.

2896. Haldimann A, Daniels LL, Wanner BL. (1998) Use of new methods for construction of tightly 290regulated arabinose and rhamnose promoter fusions in studies of the Escherichia coli phosphate 291regulon. J Bacteriol 180, 1277-1286.

2927. Balzer S, Kucharova V, Megerle J, Lale R, Brautaset T, Valla S. (2013) A comparative 293analysis of the properties of regulated promoter systems commonly used for recombinant gene 294expression in Escherichia coli. Microb Cell Fact. 12, 26.

2958. Studier FW. (1991) Use of bacteriophage T7 lysozyme to improve an inducible T7 expression 296system. J Mol Biol 219, 37-44. 
2979. Schlegel S1, Löfblom J, Lee C, Hjelm A, Klepsch M, Strous M, Drew D, Slotboom DJ, de 298Gier JW. (2012) Optimizing membrane protein overexpression in the Escherichia coli strain 299Lemo21(DE3). J Mol Biol 423, 648-659.

30010. Dubendorff JW, Studier FW. (1991) Controlling basal expression in an inducible T7 301 expression system by blocking the target T7 promoter with lac repressor. J Mol Biol 219, 45-59.

30211. Schwarz D, Junge F, Durst F, Frölich N, Schneider B, Reckel S, Sobhanifar S, Dötsch V, 303Bernhard F. (2007) Preparative scale expression of membrane proteins in Escherichia coli-based 304continuous exchange cell-free systems. Nat Protoc 2, 2945-2957.

30512. Guihard G, Boulanger P, Bénédetti H, Lloubes R, Besnard M, Letellier L. (1994) Colicin A 306and the Tol proteins involved in its translocation are preferentially located in the contact sites 307between the inner and outer membranes of Escherichia coli cells. J Biol Chem 269, 5874-5880.

30813. Cascales E, Lloubes R, Sturgis JN. (2001) The TolQ-TolR proteins energize TolA and share 309homologies with the flagellar motor proteins MotA-MotB. Mol Microbiol 42, 795-807.

31014. Celia H, Noinaj N, Zakharov SD, Bordignon E, Botos I, Santamaria M, Barnard TJ, Cramer 311WA, Lloubes R, Buchanan SK. (2016) Structural insight into the role of the Ton complex in 312energy transduction. Nature 538, 60-65.

31315. Pramanik A, Zhang F, Schwarz H, Schreiber F, Braun V. (2010) ExbB protein in the 314cytoplasmic membrane of Escherichia coli forms a stable oligomer. Biochemistry 49, 8721-8728.

31516. Pramanik A, Hauf W, Hoffmann J, Cernescu M, Brutschy B, Braun V. (2011) Oligomeric 316structure of ExbB and ExbB-ExbD isolated from Escherichia coli as revealed by LILBID mass 317spectrometry. Biochemistry 50, 8950-8956. 
31817. Sverzhinsky A, Fabre L, Cottreau AL, Biot-Pelletier DM, Khalil S, Bostina M, Rouiller I, 319Coulton JW. (2014) Coordinated rearrangements between cytoplasmic and periplasmic domains 320of the membrane protein complex ExbB-ExbD of Escherichia coli. Structure 22, 791-797.

32118. Yonekura K, Maki-Yonekura S, Homma M. (2011) Structure of the flagellar motor protein 322complex PomAB: implications for the torque-generating conformation. J Bacteriol 193, 38633233870.

32419. Kim JS, Jeong H, Song S, Kim HY, Lee K, Hyun J, Ha NC. (2015) Structure of the tripartite 325multidrug efflux pump AcrAB-TolC suggests an alternative assembly mode. Mol Cells 38, 180326186.

32720. Low HH, Gubellini F, Rivera-Calzada A, Braun N, Connery S, Dujeancourt A, Lu F, Redzej 328A, Fronzes R, Orlova EV, Waksman G. (2014) Structure of a type IV secretion system. Nature $329508,550-553$.

33021. Durand E, Nguyen VS, Zoued A, Logger L, Péhau-Arnaudet G, Aschtgen MS, Spinelli S, 331Desmyter A, Bardiaux B, Dujeancourt A, Roussel A, Cambillau C, Cascales E, Fronzes R. 332(2015) Biogenesis and structure of a type VI secretion membrane core complex. Nature 523, $333555-560$.

33422. Bakelar J, Buchanan SK, Noinaj N. (2016) The structure of the $\beta$-barrel assembly machinery 335complex. Science 351, 180-186.

33623. Unger T, Jacobovitch Y, Dantes A, Bernheim R, Peleg Y. (2010) Applications of the 337Restriction Free (RF) cloning procedure for molecular manipulations and protein expression. $J$ 338Struct Biol 172, 34-44. 
33924. Tabor S, Richardson CC. (1985) A bacteriophage T7 RNA polymerase/promoter system for 340controlled exclusive expression of specific genes. Proc Natl Acad Sci U S A. 82, 1074-1078.

34125. Studier FW, Moffatt BA. (1986) Use of bacteriophage T7 RNA polymerase to direct 342selective high-level expression of cloned genes. J Mol Biol 189, 113-130.

34326. Narayanan A, Ridilla M, Yernool DA. (2011) Restrained expression, a method to 344overproduce toxic membrane proteins by exploiting operator-repressor interactions. Protein Sci. $34520,51-61$.

34627. Stuchlík S, Turna J. (1998) Overexpression of the FNR protein of Escherichia coli with T7 347expression system. Folia Microbiol (Praha) 43, 601-604.

34828. Doherty AJ, Connolly BA, Worrall AF. (1993) Overproduction of the toxic protein, bovine 349pancreatic DNaseI, in Escherichia coli using a tightly controlled T7-promoter-based vector. 350Gene 136, 337-340.

35129. van den Ent F, Löwe J. (2006) RF cloning: a restriction-free method for inserting target 352genes into plasmids. J Biochem Biophys Methods 67, 67-74.

35330. Jeong J, Yim H, Ryu J, Lee H, Lee J, Seen D, Kang S. (2012) One-step sequence- and 354ligation-independent cloning as a rapid and versatile cloning method for functional genomics 355studies. Appl Environ Microbiol 78, 5440-5443.

35631. Bénédetti H, Lazdunski C, Lloubes R. (1991) Protein import into Escherichia coli: colicins A 357and E1 interact with a component of their translocation system. EMBO J 10, 1989-1995. 
35832. Derouiche R, Bénédetti H, Lazzaroni JC, Lazdunski C, Lloubes R. (1995) Protein complex 359within Escherichia coli inner membrane. TolA N-terminal domain interacts with TolQ and TolR 360proteins. J Biol Chem 270, 11078-11084.

36133. Konovalova A, Silhavy TJ. (2015) Outer membrane lipoprotein biogenesis: Lol is not the 362end. Philos Trans R Soc Lond B Biol Sci 370, 1679.

36334. Ringquist S, Shinedling S, Barrick D, Green L, Binkley J, Stormo GD, Gold L. (1992) 364Translation initiation in Escherichia coli: sequences within the ribosome-binding site. Mol 365Microbiol 6, 1219-1229.

366

367i. Acknowledgements

368We would like to thank M. Petiti, L. Houot, H. Célia and D. Duché for careful reading. ED and 369RL are are funded by the Centre National de la Recherche Scientifique, the Aix-Marseille 370Université and two grants from the Agence Nationale de la Recherche (ANR-10-JCJC-1303-03 371and ANR-14-CE09-0023, respectively) 
(a)

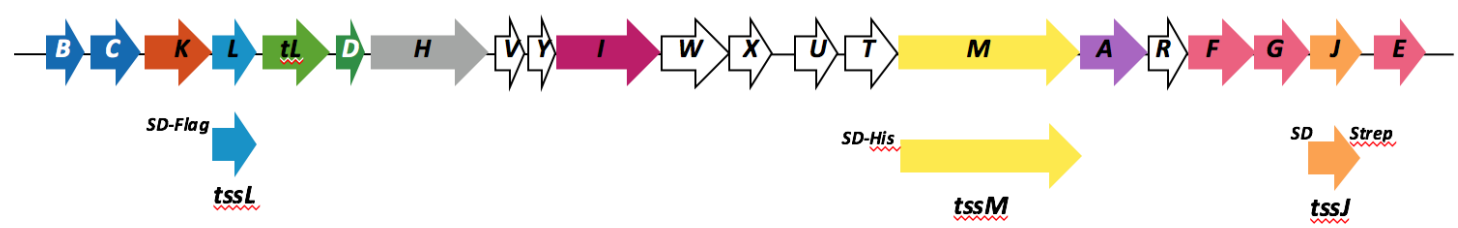

(b)

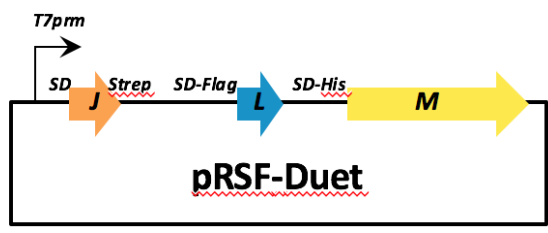

(c)

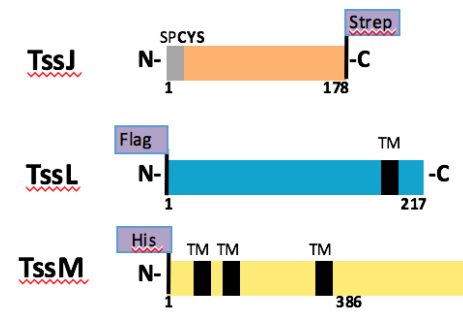

372

373Figure 1: Cloning of the synthetic tss $\boldsymbol{J L M}$ operon encoding the T6SS membrane core

374complex. (a) The tssL, tss $M$ and $t s s J$ genes were PCR amplified from the entero-aggregative $s c i$ 3751 T6SS operon. DNA sequences were added encoding an optimized RBS at the 5' end of each 376gene and sequences encoding a C-terminal Strep-II tag for TssJ and N-terminal $6 \times$ His and Flag 377tags for TssM and TssL, respectively. (b) The tssJLM artificial operon was cloned in the pRSF378Duet vector. (c) Schemes representing the protein constructs, the sub-domain boundaries and 379some indicated characteristics (TM, transmembrane segments; SP, signal peptide; CYS, acylated 380cysteine). 